\title{
Menjadi Guru : \\ yang Inovatif dalam pembelajaran masa Pandemi
}

\author{
Ihwani Pangesa \\ E-mail : ihwani.pangesa0580@student.unri.ac.id \\ Program Studi Pendidikan Bahasa dan Sastra Indonesia, Universitas Riau
}

\section{Pengantar}

Jika membahas tentang guru, apa yang terlintas di fikiran anda? Guru merupakan sosok seorang yang sangat dapat dipercayai dan bisa diikuti atau ditiru. Guru tidak hanya bertanggung jawab untuk mengajar, untuk memastikan kecerdasan peserta didik dalam mata pelajaran saja, melainkan bertanggung jawab atas moral dan etika peserta didik. Sebagai seorang guru harus memiliki kompetensi profesional yang sesuai dengan tugas dan tanggung jawabnya. Guru juga harus memiliki kompetensi sosial agar dapat saling memotivasi peserta didiknya. Guru juga harus memiliki cara tersendiri dalam mengajar peserta didiknya. Agar suasana pembelajaran terasa menyenangkan dan selalu berjalan dengan optimal.

\section{Tindakan dapat dilakukan seorang guru dalam pembelajaran fisika pada masa pandemi}

Dalam melaksanakan pembelajaran online di masa pandemi, tindakan yang dapat dilakukan oleh seoran guru yang pertama yaitu :

a. Mempersiapkan pendidik dan peserta didik.

Dalam proses belajar mengajar hal ini sangat diperlukan, sebab bagaimana menurut anda jika seorang guru ada namun tidak anak murid yang akan di ajarnya, begitu juga sebaliknya bagaimana jika beberapa murid yang ada namun guru yang sebagai pendidik tidak ada? Dalam proses belajar mengajar sangat diperlukan kedua posisi tersebut. Sebab jika tidak ada, maka proses belajar mengajar tidak akan pernah berlangsung.

b. Pengalaman dalam pratikum.

Dalam hal ini setiap guru harus memiliki pengalaman dalam berpratikum, sebab pada mata pelajaran fisika juga terdapat berbagai pratikum yang menggunakan alat. Jika seorang pendidik tidak terampil dalam pratikum tersebut maka, sebuah proses pembelajaran tidak akan berlangsung dengan sebagai mana mestinya. Jika seorang guru tidak memiliki keterampilan dalam berpratikum maka pembelajaran ini selamanya tidak 
akan dapat berlangsung, sebab dalam percobaan pratikum ini menentukan beberapa ketentuan dari apa yang kita ukur. Jika sekali saja ukurannya salah, maka seterusnya akan salah juga.

c. Memberikan materi sebelum pembelajaran dimulai.

Pada saat pembelajaran akan dimulai setiap guru harus selalu memberikan materi yang akan di pelajari pada hari itu kepada peserta didiknya. Dengan adanya beberapa materi yang diberikan peserta didik dapat terlebih dahulu membaca materi pembelajaran pada saat itu, sehingga mereka bisa memahami apa yang akan di pelajari, dan jika tidak paham akan suatu hal, maka dapat di pertanyakan pada saat pembelajaran berlangsung. Jadi hubungan timbal balik antara pendidik dan peserta didik dapat terlaksanakan dengan adanya beberapa pertanyaan dari peserta didik dan jawaban dari pendidik.

d. Memberikan video pembelajaran.

Video pembelajaran pada saat belajar ini dapat dijadikan sebagai faktor pendudukung untuk kelancaran proses pembelajaran. Dengan adanya berbagai video yang di sampaikan melalui link youtube misalnya. Dengan adanya video pembelajaran ini juga dapat memberikan pengetahuan yang dapat dicontohkan oleh peserta didiknya. Karena pada video tersebut jika terdapat beberapa praktik maka peserta didik dapat melihatnya dan dapat di praktikkan. Setidaknya terdapat beberapa tata cara dalam sebuah praktek pada video pembelajaran.

e. Membuat rangkuman pembelajaran

Jika suatu pembelajaran sudah berjalan, tentu saja harus ada rangkuman dari apa yang dipelajari pada hari itu. Rangkuman ini bertujuan untuk meringkas materi pembelajaran yang di pelajari pada hari itu. Rangkungan ini lebih berisi ke inti atau pokok pembelajaran yang sudah di pelajari.

Dalam kontek belajar daring di masa covid-19, kualitas belajar tidak diharapkanmenurun tetapi terus meningkat. Jika kualitas belajar menurun, maka dapat memberikandampak mutu capaian belajarwawasan dan pengalamannya(Zulhafizh, Atmazaki, \& Syahrul,2013). Kegiatan belajar berupaya memberikan pengalaman kepada mahasiswa sehingga terjadi penambahan wawasan dan pengalaman.Wawasan 
dan pengalaman sebagai pendukung dan pengarah mahasiswa untuk lebih baik. Dalam pembelajaran akan ada prosesmental (Hall, 2003) yang dapat menentukan arah perilaku dan perbuatan (Mustafa \& Zulhafizh, 2017). Lebih lanjut Hall (2003) menjelaskan karena dalam kegiatan belajar terjadisimulasi dan stimulus sehingga mahasiswa mendapat pemahaman dan pengalaman. Apabila stimulus berlangsung dengan baik, maka akan menghasilkan suatu pengetahuan bagi mahasiswa (Jangel al,2020).

\section{Sarana pendukung}

Sarana pendudkung yang dapat digunakan dalam proses pembelajan Online ini terdapat beberapa media. Namun, yang dipaparkan ini merupakan sarana pendukung proses pembelajaran pada mata pelajaran Fisika. Beberapa media yang dapat digunakna yaitu :
a. Google Classroom
b. Google meet/zoom
c. WA
d. Youtube
e. Laptop / Hp
f. Kuota internet
g. Jaringan
h. Situs-situs pendidikan

i. Pakar-pakar pada bidang pendidikan fisika

Setiap pembelajaran yang dilalui mahasiswa tentu akan melahirkan berbagai pengalaman baru, khususnya waktu dan suasana yang baru. Kegiatan eksplorasi ini sebagai tindakan yang mendorong mahasiswa untuk aktif dalam pembelajaran. Pengalaman baru akan diperoleh selama mahasiswa mengikuti pembelajaran yang disajikan pendidik atau pun mahasiswa. Mahasiswa akan mengalami kesulitan mengelola ide kreatifnya jika tidak memiliki bekal yang memadai. Mustafa dan Zulhafizh (2018a\&b) penguasaan informasi memudahkan mahasiswa untuk mengeksplorasi informasi yang ada sehingga dapat melahirkan pengalaman baru. 


\section{Tindakan solutif}

Jika Google Classrom tidak bisa dimaksimal kan, dalam pembelajaran yang akan berlangsung maka dapat menggunakan media yang lainnya. Jika misalnya dalam pengiriman tugas, Google Classroom tidak dapat berproses dengan semestinya. Maka sebagai seorang guru harus memiliki strategi yang lainnya untuk pengumpulan tugas ini. misalnya bisa melalui WhatsApp Group, Email, Website.

Namun jika seorang siswa memiliki beberapa kendala dalam pelaksanaan proses belajar mengajar, maka ia juga harus mencari solusi yang tepat agar pembelajaran tetap berjalan dengan lancar dan tidak ketinggalan oleh teman yang lainnya. Misalnya seorang siswa yang terkendala dalam jaringan, maka ia harus bisa mencari tempat yang memiliki jaringan yang bagus dan kuat, ataupun jika tidak terdapat jaringan di tempat sekitar, maka ia bisa mencari wifi di sekitarnya, maka pembelajaran akan tetap berjalan dengan baik dan tidak akan ketinggalan oleh teman yang lainnya.

Selain itu jika terkendala dalam materi, atau memiliki materi yang terbatas, maka Guru dan Siswa dapat mengatasi hal ini mengan cara mencari materi tambahan dari berbagai buku ataupun file yang berbentuk pdf, melihat dari penelitian-penelitian dan pengamatan yang sebelumnya sudah mencapai, dan berbagai jurnal-jurnal dengan adanya hal ini maka Guru dan Siswa dapat menambah wawasan baru untuk mendpatkan pengetahuan yang lebih mendalam.

\section{Kesimpulan}

Kesimpulan yang diperoleh antara lain, yakni mahasiswa harus bisa membina aktivitas belajarnya di masa pandemi Covid-19 dengan baik, pada kategori tinggi. Aktivitasnya seperti dapat mengatasi sendiri masalah yang terjadi pada proses pembelajaran, apa yang kurang bisa dicari secara mandiri maupun dengan cara berkelompok. seperti kegiatan belajar sangat membantunya memahami informasi yang dipelajari. Aktivitas belajar bisa saja gagal ketika mahasiswa tidak mampu memahami informasi tersebut.

\section{Referensi}


Link Google Schoolar

https://osf.io/preprints/5jb3t/

Zulhafizh, Atmazaki, \& Syahrul R. (2013). Kontribusi Sikap dan Motivasi Belajar Siswaterhadap Hasil Belajar Bahasa Indonesia.Jurnal Bahasa, Sastra dan Pembelajaran,1(2), 13-28.

Mustafa, M. N., \& Zulhafizh. (2017). Building the Professionalism of Teachers as an Effortto Improve Education. In Husein, R, et al (Eds.),International Seminar and AnnualMeeting 2017 Fields of Linguistics, Literature, Arts, and Culture,Medan, 449

Jang, J., Purwanto, A., Purnamasari, D., Ramdan, M., Hutagalung, L., Akuba, S., Sulistiyadi,A., Pramono, R., \& Bernarto, I. (2020). Pendidikan Vokasi BTEC UK di Indonesia:Studi Fenomenologi Esensi Pengalaman Peserta Didik.Jurnal Kependidikan: JurnalHasil Penelitian dan Kajian Kepustakaan di Bidang Pendidikan, Pengajaran danPembelajaran, 6(1), 1-12. doi:https://doi.org/10.33394/jk.v6i1.2319.

Mustafa, M. N., \& Zulhafizh. (2018a). Information Mastery by Teachers as A Strategy toSucceed in the Implementation of Teaching and Learning Activities.InternationalSeminar and Annual Meeting BKS-PTN Wilayah Barat, 516-523.

\section{Data penulis}

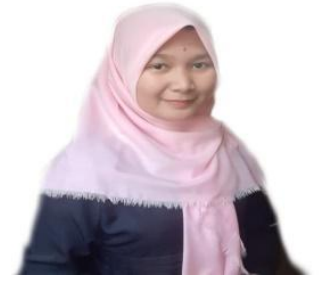

Ihwani Pangesa, lahir di Pangean, 10 November 2001. Ia tamat dari SMAN 1 Pangean pada tahun 2020, dan ia melanjutkan studi pada Program Studi Pendidikan Bahasa dan Sastra Indonesia, FKIP Universitas Riau melalui Jalur SNMPTN ( Seleksi Nasional Masuk Perguruan Tinggi, sekarang ia menempuh pendidikannya pada semester Tiga di Kampus Tercinta.

Kontak : 
Hp / WA : +6285294140171

Email : ihwani.pangesa0580@student.unri.ac.id

: ihwanipangesa10@gmail.com 